Musées, Patrimoine et Culture scientifiques et techniques

\title{
L'observation du Patrimoine et de la Culture Scientifiques et Techniques : un défi collectif et un nouveau chantier pour l'OCIM
}

Louis-Jean Gachet

\section{OpenEdition}

\section{Journals}

Édition électronique

URL : http://journals.openedition.org/ocim/197

DOI $: 10.4000 /$ ocim. 197

ISSN : 2108-646X

Éditeur

OCIM

Édition imprimée

Date de publication : 1 novembre 2009

Pagination : $5-6$

ISSN : 0994-1908

\section{Référence électronique}

Louis-Jean Gachet, «L'observation du Patrimoine et de la Culture Scientifiques et Techniques : un défi collectif et un nouveau chantier pour I'OCIM », La Lettre de I'OCIM [En ligne], 126 | 2009, mis en ligne le 01 novembre 2011, consulté le 05 mai 2019. URL : http://journals.openedition.org/ocim/197 ; DOI :

10.4000/ocim. 197 


\section{L'observation du Patrimoine et de la Culture Scientifiques et Techniques : un défi collectif et un nouveau chantier pour I'OCIM}

L'OCIM approche de son 25e anniversaire.

Ce quart de siècle est un seuil symbolique pour un service qui a joué à sa manière un rôle contributif, discret mais non négligeable, dans l'histoire de la muséologie contemporaine, à la jointure de différentes sagas culturelles et patrimoniales françaises des trente dernières années, celle des muséums d'abord, celle des musées et du patrimoine dans leurs diversités ensuite, celle de la culture scientifique et technique enfin, pour ne citer que celles qui l'ont concerné directement et le concernent toujours.

Avec son corpus qui approche des 800 articles et des 4000 pages, sous la signature de 650 auteurs, La Lettre de l'OCIM, délivrée avec sa régularité bimestrielle, est définitivement inscrite dans les sources incontournables pour la profession. Le secteur formation de son côté, avec ses 150 sessions très spécialisées tenues depuis 1986, pour une population de près de 3000 professionnels, a su marquer le paysage de la transmission des savoirs et savoir-faire dans les domaines de la muséologie et apposer une marque de fabrique qualitative spécifique à l'OCIM. L'énumération pourrait ainsi se poursuivre, pour donner idée du travail accompli et l'Office n'a pas à rougir d'un bilan tout à fait reconnu. L'année 2010 fournira bien l'occasion de retracer de manière plus détaillée l'itinéraire de cet organisme original qu'est l'OCIM.

Mais s'il fallait s'interroger sur l'avenir, ce qui n'aurait rien d'étrange, compte tenu de l'ambition naturelle de toute organisation de poursuivre sa trajectoire, il est paradoxal de constater qu'en ces temps mouvants, notamment dans les champs culturels, l'OCIM s'est vu confier par ses tutelles, le ministère de l'Enseignement supérieur et de la Recherche et l'université de Bourgogne une mission nouvelle, ambitieuse, relevant d'un principe de stabilité et s'inscrivant obligatoirement dans la durée : mettre en place un Observatoire du Patrimoine et de la Culture Scientifiques et Techniques.

Jusqu'alors défini comme un «centre de ressources spécialisé en muséographie et muséologie des sciences et des techniques, au service des musées, des CCSTI et des établissements d'enseignement supérieur ainsi que des autres acteurs de la culture scientifique », l'OCIM a indiscutablement vu au fil du temps s'élargir et se diversifier l'ensemble de ses interlocuteurs professionnels et ses thématiques de travail. Mais pour autant, il n'a constitué jusqu'alors qu'un des très nombreux contributeurs implicites au champ extrêmement large et diffus de la CST. Parions sur le fait que l'OCIM aura capacité à relever ce défi passionnant de répondre aux attentes en ce domaine, et de développer des compétences qu'il n'avait pas véritablement développées de manière explicite jusqu'alors et que l'on pourrait résumer à travers le mot « expertise». 
Dans cette entreprise, les atouts de l'OCIM ne manquent pas : des modes d'intervention concrets et rôdés dans les registres de la formation, de l'édition, au contact rapproché de professionnels, un capital d'information, de connaissance des réseaux, de savoir faire, toutes ressources qu'en d'autres circonstances de création ex nihilo, on rêverait d'associer au plus vite à une mission d'observation. Mais un tel chantier appelle nécessairement une réorganisation méthodologique de l'ensemble du service, le développement de la réflexion stratégique, sans compter la mise en œuvre de compétences et d'outils nouveaux, notamment dans le domaine des bases de données. Depuis plusieurs mois, l'OCIM se prépare à cette mutation. Afin de mener à bien cette nouvelle mission d'observation, une équipe a été progressivement mise en place à partir de décembre 2007. Y ont déjà apporté leur concours - dans le cadre de missions contractuelles souvent très courtes - Astrid Chevolet, Mélodie Breton, Fabien Lacaille, Julien Couteaux, Jean-Louis Lacroix, Olivier Soichot et Patrice Charon, Florence Belaën assurant la charge de chef de projet depuis décembre 2008.

Au terme d'une première phase de travail au cours de laquelle a été conduite une sérieuse exploration méthodologique, l'OCIM est en mesure de proposer deux contributions.

Le premier volet est la présente Lettre, coordonnée par Florence Belaën, et dédiée aux thématiques de l'observation et de l'évaluation. Elle se veut un point d'étape, sans prétention exhaustive, sans oblitération des travaux d'ores et déjà publiés, tout simplement la restitution de nouvelles analyses et regards critiques, mais aussi l'apport de comptesrendus d'expériences, bref un versement de nouveaux matériaux au dossier.

Joëlle le Marec, Serge Chaumier, Jacqueline Eidelman, Jean-Pierre Cordier, Séverine Dessajan, apportent leurs contributions d'experts du domaine. D'autres professionnels, Olivier Las Vergnas, Isabelle Süss, Aymard de Mengin livrent également ici des comptesrendus d'expériences ou ont accepté comme Jean-Michel Tobelem, Dominique Le Tirant, Viviane Jovet de se prêter au jeu de l'interview. Que tous soient ici remerciés. Mais que soit particulièrement exprimée notre gratitude à René Rizzardo, fondateur de l'Observatoire des Politiques Culturelles et directeur de cette structure de 1989 à 2002, et qui a accepté de consacrer du temps à l'équipe de l'OCIM et qui répond ici à nos questions. Enfin, Florence Belaën présente l'état de la réflexion sur l'Observatoire du Patrimoine et de la Culture Scientifiques et Techniques en cours de mise en place et ses perspectives opérationnelles.

Le second volet est constitué par les Rencontres des 26 et 27 novembre 2009, organisées grâce au soutien de la Région Bourgogne, et accueillies au Conseil régional puis par le Grand Dijon, ainsi que par le Jardin des Sciences de Dijon, et placées sous l'intitulé Observer, questionner, accompagner : un observatoire pour la culture scientifique et technique. Leur préparation a donné lieu à de nombreux entretiens, consultations, afin d'affiner les intuitions, tester les idées et aboutir à une première mise en visibilité sous forme d'un forum des acteurs professionnels, des décideurs, des chercheurs et de tous les partenaires intéressés à l'émergence de cette structure, en y associant les contributions les plus larges provenant d'autres domaines que les milieux traditionnels de la CST.

L'observation ne se décrète pas, ne s'impose pas. Les conditions de sa mise en œuvre ne peuvent émerger que peu à peu, dans un contexte d'adhésion à un cadre collectif, partagé, convenant à l'ensemble des professionnels et institutions du domaine, cadre grâce auquel ils disposeront de données analytiques fiables pour progresser dans leurs missions. Et au cœur de ce projet, l'OCIM trouve inspiration renouvelée à servir la collectivité professionnelle en honorant un des plus beaux termes qui le définissent : la coopération. 